\title{
The International Medical Society of Paraplegia and its Journal
}

The International Medical Society of Paraplegia (IMSOP) was formed in the Old Gymnasium at Stoke Mandeville Hospital in 1961. For some years before that the doctors accompanying their teams to the International Stoke Mandeville Games had met relatively informally for a 'scientific meeting'. I well remember the first scientific meeting I attended in 1958; for the doctors training at Stoke Mandeville the end of July was a hectic time, we had to assist in the running of the Games, treat sports injuries and prepare presentations for the scientific meeting. There was a sort of programme for the scientific meeting but if important foreign doctors brought unannounced papers they were always allowed to present them. Timekeeping was entirely by Ludwig Guttmann who invariably chaired the entire session, summarised the proceedings and told speakers what they should have said! Ludwig Guttmann who had founded the National Spinal Injuries Centre at Stoke Mandeville hospital had a masterful grasp of all topics relevant to paraplegia and pursued his objectives with immense energy. In those early days doctors working in spinal cord injuries were relatively isolated within their own medical communities and the opportunities to discuss their clinical problems with others was taken eagerly and often led to heated discussions - I can well remember two doctors, who subsequently became very influential members of IMSOP, struggling for the microphone - one had the microphone and the other the wire which was fortunately strong, the subject of the dispute I believe was gastro-intestinal bleeding following spinal cord injury!

In 1961 Professor Pierre Houssa suggested that scientific meetings should be formalised and that an international society should be set up, this idea was enthusiastically adopted as his own by Ludwig Guttmann who became the first President of IMSOP. At the time of the First Annual General Meeting the founder members were lined up against a brick wall and the hospital photographer took a photo (Figure 1). In Figure 2 you will see Ludwig Guttmann, Piere Houssa and the 'young Phillip Harris'. Annual General Meetings and Scientific Meetings of the society continued to be held in the gymnasium of Stoke Mandeville Hospital until the new Sir Henry Floyd lecture theatre and Post Graduate Centre were built at Stoke Mandeville Hospital in 1970. In 1964 an additional scientific

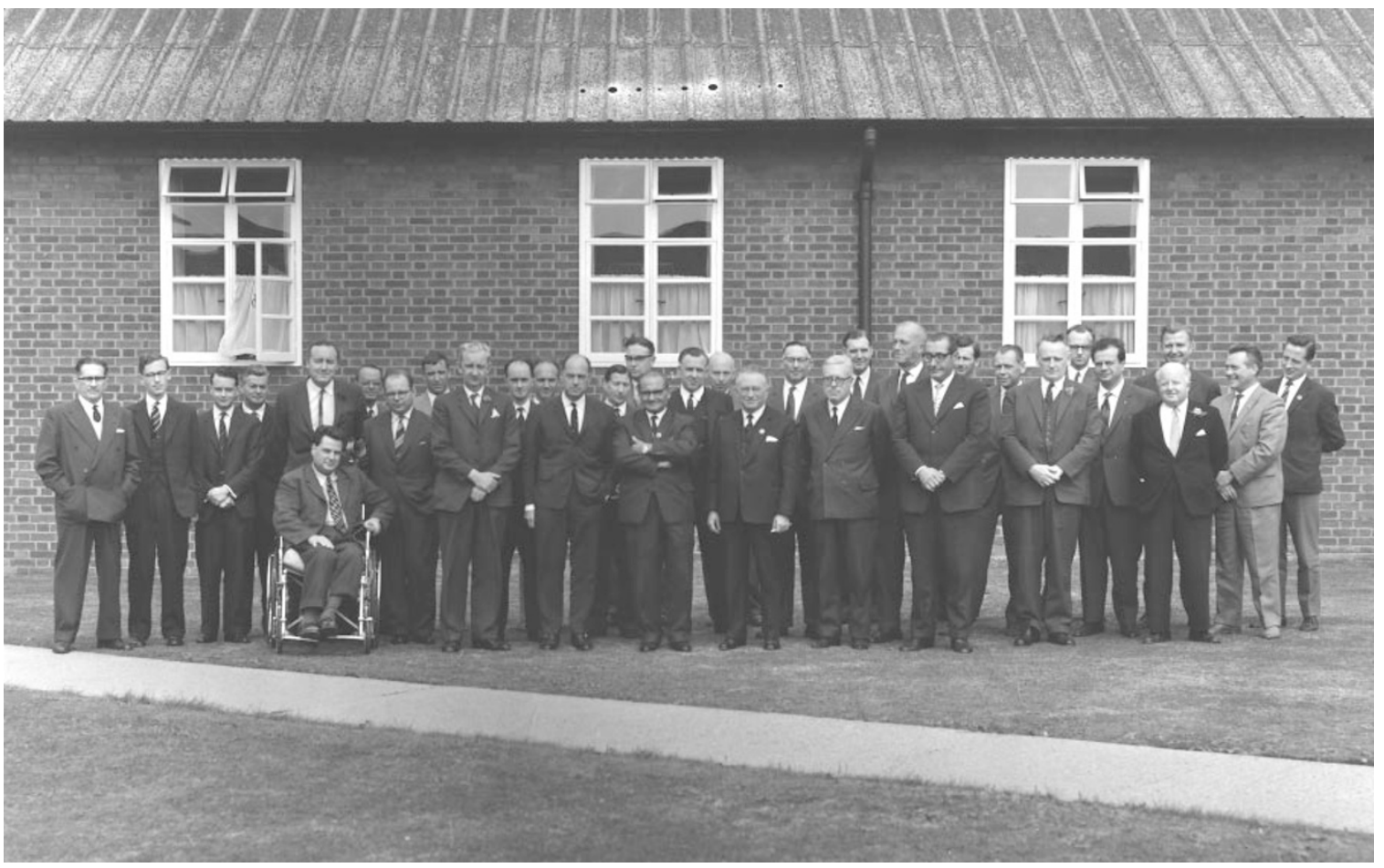

Figure 11961 Photograph of the Founder Members at the First Annual Scientific Meeting of the International Medical Society of Paraplegia at Stoke Mandeville 


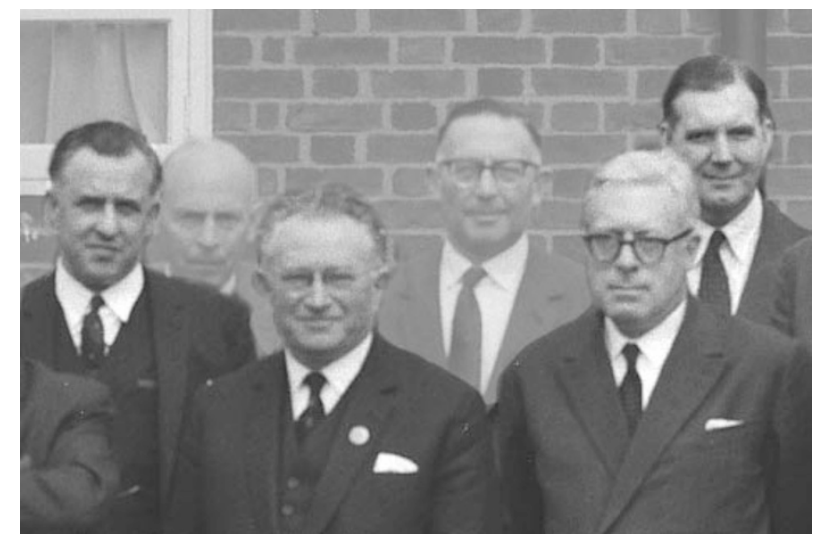

Figure 2 Phillip Harris, Ludwig Guttmann, Pierre Houssa, Jim Cosbie-Ross

meeting was held in Tokyo in association with the Paralympics under the patronage of the Crown Prince of Japan. In 1972 the Annual Scientific Meeting was held in Heidelberg in association with the Paralympics and for the next decade meetings continued to be held at Stoke Mandeville for 3 years out of four. During the 1970s the meetings were held at Stoke Mandeville every 2 or 3 years, other meetings being with the Paralympics or at other venues. Meetings at Stoke Mandeville became less frequent and the last meeting there was in 1991, Stoke Mandeville lecture theatre only seats 130 and I doubt if we will ever have a full meeting of the Society there again, however a regional meeting is under consideration. The Society still attempts to have its annual meeting in the same city and at the same time as the Paralympics and this will indeed occur in Sydney in 2000. While reviewing the history of our annual meetings I was impressed to see that meetings that orignally were planned days ahead with the programme substantially altered during the meeting have developed into meetings which are planned 4 years in advance!

The Society decided that it wished to publish it own journal under the title of PARAPLEGIA and the first volume came out in 1963. Ludwig Guttmann was the Editor and Phillip Harris and Jim Cosbie-Ross were Assistant Editors. In the early days each paper required to have a summary, a 'résumé' and a 'Zusammenfassung' (the requirement for translation of the summary into French and in German was eventually abandoned as the failure of authors to provide them was holding up publication). Many of the papers in the early numbers had been presented at the Annual Scientific Meeting and a verbatim account of the ensuing discussion was often included, sometimes the Editor did not have time to edit out the insults that were exchanged! Ludwig Guttmann personally 'peer-reviewed' many of the papers that were submitted unless there was some subject in which he did not consider himself to be an expert and reviewing of these and other matters were delegated to his assistant editors. Eventually Sir Ludwig got a parttime secretary to assist him in this work. The journal had an imediate success and was well produced and quite cheap.

When Sir Ludwig Guttmann died in 1980 Phillip Harris, who had been a loyal and hardworking Assistant Editor for 17 years, took over as Editor and after 17 years as Editor he is now retiring from his onerous duties. Under Phillip's editorship PARAPLE$G I A$ became the premier peer-reviewed journal in its field and is now published monthly. In April 1996 the old title PARAPLEGIA was changed to the now more appropriate title of SPINAL CORD. The present success and authority of SPINAL CORD and indeed the success of IMSOP are largely due to the efforts of Phillip Harris over the last 34 years. We acknowledge out debt to him with gratitude.

IMSOP is no longer the small debating club which it was, its membership exceeds 1200 and this year's highly successful annual meeting in Innsbruck was attended by 380 delegates. The questions and discussions following platform and poster presentations are the very heart of our scientific meetings. The Scientific Committee is constantly striving to maintain this 'heart' in the face of increasingly large meetings.

Those countries represented at our early meetings now have effective, sophisticated but still substantially different methods of delivering medical care to persons with spinal cord injuries and diseases. Even in these countries the recognition of spinal cord injuries as a separately unique and important speciality is sometimes under threat, the changing pattern of healtheconomics forces us to adapt to maintain and improve facilities that are already established. In much of the developing world IMSOP with the generous assistance of the Swiss Interdevelopment Fund is helping our colleagues to establish spinal injury facilities. Our research, development and teaching must go on, there is still much for the Society and its journal to achieve in the years ahead.

Hans Frankel President of IMSOP 